This is a self-archived - parallel published version of this article in the publication archive of the University of Vaasa. It might differ from the original.

\title{
The imitation-innovation link, external knowledge search and China's innovation system
}

Author(s): Wu, Jie; Zhang, Xinhe; Zhuo, Shuaihe; Meyer, Martin; Li, Bin; Yan, Haifeng

Title: $\quad$ The imitation-innovation link, external knowledge search and China's innovation system

Year: $\quad 2020$

Version: Accepted manuscript

Copyright (C) 2020 Emerald Publishing Limited. This manuscript version is made available under the Creative Commons Attribution-NonCommercial 4.0 International (CC BY-NC 4.0) license, https://creativecommons.org/licenses/by-nc/4.0/

Please cite the original version:

Wu, J., Zhang, X., Zhuo, S., Meyer, M., Li, B. \& Yan, H. (2020). The imitation-innovation link, external knowledge search and China's innovation system. Journal of Intellectual Capital 21(5), 727-752. https://doi.org/10.1108/JIC-05-2019-0092 


\title{
THE IMITATION-INNOVATION LINK, EXTERNAL KNOWLEDGE SEARCH AND CHINA'S INNOVATION SYSTEM
}

\author{
Jie $\mathrm{Wu}$ \\ Department of Management and Marketing, University of Macau, Zhuhai, Macao \\ Xinhe Zhang \\ University of Macau, Zhuhai, Macao \\ Shuaihe Zhuo \\ Macau University of Science and Technology, Macao, China \\ Martin Meyer \\ King's College, University of Aberdeen Business School, Aberdeen, UK and \\ School of Technology and Innovation, University of Vaasa, Vaasa, Finland \\ Bin Li \\ Shanghai University of Finance and Economics, Shanghai, China, and \\ Haifeng Yan \\ East China University of Science and Technology, Shanghai, China
}




\title{
THE IMITATION-INNOVATION LINK, EXTERNAL KNOWLEDGE SEARCH AND CHINA'S INNOVATION SYSTEM
}

\begin{abstract}
How is imitation tied to innovation? This question is addressed in the context of China's innovation system in the 2000s where Chinese industrial firms simultaneously implement innovation and imitation strategies in their new product developments. In contrast to earlier innovation studies in which innovation and imitation are unrelated, this study reveals that imitation complements innovation, and the extent of Chinese firms' external knowledge search affects the complementary relationship between imitation and innovation. These findings add important insights to the innovation management literature and contribute empirical evidence to the interplay of innovation and imitation enhancing national innovation system.
\end{abstract}

Keywords: Innovation; imitation; new product development; knowledge search; China innovation system 


\section{INTRODUCTION}

How is imitation tied to innovation? Two lines of research have addressed the topic of the relationship between imitation and innovation. In the economics literature, the argument is often made that imitation is related to convergence or catching up of frontier firms (Aghion, Harris, Howitt and Vickers, 2001; Davidson and Segerstrom, 1998; Zeng, 1993). In this literature, innovation and imitation were conceptualized as unrelated, as each was considered to embody a distinct mindset. While innovation is a necessary condition for an organization's survival and growth, imitation is often considered as a spontaneous and haphazard act impeding innovation (Ethiraj, Levinthal and Roy, 2008; Lenox Rockart and Lewin, 2006; Rivkin, 2000, 2001; Winter and Szulanski, 2001). Some innovation management scholars, however, provide a different argument. Imitation is not contradictory to, but rather supportive of, innovation because it develops capabilities consistent with innovation (Bolton, 1993; Hurley and Chater, 2005; Iacoboni, 2009; Augier and Teece, 2005; Wu et al., 2017).

The question thus arises whether imitation is an enabler or a hindrance of innovation. The discrepancy between the two arguments on the relationship between imitation and innovation may be partly due to different foci. The first line of research tends to concentrate on the imitationinnovation problem of finding effective ways of reconciling the two strategies, while the second line tends to focus on the assistance of imitation to innovation. Anecdotal and empirical evidence

of a few consummate innovators also acting as imitators (e.g., Wal-Mart, IBM, Apple, Procter \& Gamble, Sherwin-Williams) has suggested a more complicated relationship. "Even if we're trying to innovate, we also want to know what other people have out there, so some of the innovation ... is driven by imitation", exclaimed by Lionel L. Nowell, former senior vice president and treasurer, PepsiCo. As Levitt (1966: 70) notes, "to behave lopsidedly as if innovation were a messiah, and 
especially at the awful expense of a realistic appreciation of the fructifying power of more systematic imitation, would be an even greater mistake." Many successful organizations have used imitation as an important strategy to outperform competitors and combined it with innovation to offer a superior product or service features, in particular, the firms from developing economies (e.g., Tata and Ranbaxy in India, Odebrecht and Promon in Brazil, Huawei, and Lenovo in China) having successfully emerged as key players challenging dominant innovators in international markets. Drawing on these business realities, we define imitation as an independent, rather than equivalent, to innovation: copying innovations developed by others (i.e., imitation) will usually be cheaper than executing a firm's innovative activity (Cappelli et al., 2014), and conceptualize the relationship between imitation and innovation as the complementarity.

Although several innovation management scholars have argued that imitation only provides cost benefits under certain conditions and are less beneficial than innovation in providing new ideas and technologies, these scholars have tended to conceptualize imitation as part of an overarching innovation strategy (Arora and Gambardella, 1990; Lichtenthaler, 2009). For example, by distinguishing between pure knowledge transfer and "reflective imitation," which requires active adaptation of technology to establish a new setting and reflects a new user's particular requirements, Bolton (1993) elevated reflective imitation strategy beyond simple copying and knowledge transfer to something closer to innovation strategy. On the other hand, Posen et al. (2013, p. 151) characterized imitation as "a search process in which a firm attempt to replace a subset of its attributes with those of a high performing firm." Moreover, previous studies have typically criticized findings from business cases, ideas from managerial practices, and anecdotes that provide compelling accounts of the complementarity between innovation and imitation. Moreover, whether the relationship between imitation and innovation is affected by certain 
contextual variables has not been studied. This represents a significant lacuna because the interplay of innovation and imitation does not occur in a vacuum and is subject to specific organizational characteristics. To effectively manage these two types of strategies, understanding organizational conditions under which imitation and innovation interact is at least as important, if not more important, than determining the relationship between the two.

We investigate the relationship between innovation and imitation in new product development undertaking by Chinese industrial firms in the 2000s. This is an excellent context to examine the effects of different combinations of imitation and innovation on new product development, as imitation and innovation are two important strategies for Chinese industrial firms to develop cutting-edge products (Bi, Sarpong, Botchie, and Rao-Nicholson, 2017; $\mathrm{Wu}, \mathrm{Ma}$, and Zhuo, 2016). On the one hand, many Chinese industrial firms focus on specialization on OEM business, which enables them to learn new technologies avoiding very costly R\&D expenditure through imitating advanced technologies embedded in the parts or subsystems provided by more developed countries (Wu, Ma, and Zhuo, 2016; Wu, Zhuo, and Wu, 2017). On the other hand, Chinese firms' catch-up strategy is featured by intertwined imitation and innovation. For example, the process of new product development from imitation to innovation prompts Chinese firms to invest in-house $\mathrm{R} \& \mathrm{D}$ to improve innovative capacity (Bi et al., 2017). Moreover, the historical context of China's innovation system in the 2000s evolving into an innovative champion reflects a leap from imitation to innovation over a technologically turbulent period.

This article thereby makes three contributions. First, in search of evidence of the existence of complementarity, we present a rigorous and careful study to unravel the intricate relationship between imitation and innovation strategies. This study provides a theoretical foundation and examines systematic data for analysing the complementarity between innovation and imitation 
strategies. Second, rather than merely searching for complementarity, we aim to identify the contextual variables that affect such complementarity. We identify external knowledge search as an important contextual variable that influences the extent to which imitation and innovation activities complement each other that heretofore has remained unexplained. Third, the findings contribute scarce empirical evidence to the debate outlined at the beginning.

The article proceeds as follows. We first review the relevant literature and China innovation system in the 2000s. Second, we build on algebraic lattice theory to show the existence of complementarity. Third, we discuss the theoretical issues surrounding complementarity and provide a general model. Fourth, we outline the empirical context for assessing the complementarity of imitation and innovation and discuss the measures of key variables and explain econometrical modelling. Fifth, we present the results of the analyses and the robustness analyses. Finally, we discuss the contributions and limitations of the study.

\section{LITERATURE REVIEW}

\section{Imitation and Innovation}

Typical theorizing on the relationship between innovation and imitation conceptualizes them as two idealized strategic archetypes embodying different approaches and capabilities. Innovation is assumed to serve as a basis for sustainable advantage, while imitation is treated as an inferior activity that is the antithesis of innovation (Westney, 1986). However, increasing anecdotal and empirical evidence suggest that imitation and innovation are more complex than previously assumed. Consequently, some scholars have begun examining the complex relationship between innovation and imitation. For example, Levitt (1966) suggested that organizations are motivated by competition to treat imitation as a survival and growth strategy and that even the largest 
innovation-active organizations must be involved in imitation. Nelson and Winter (1985) contended that when an imitator independently solves a problem with limited clues regarding details of the imitatee's performance, the imitator really acts as an "innovator." Building on these insights, Bolton (1993) conceptualized innovation as a "learning-by-doing" activity that is rooted primarily in a firm's internal competencies and involves experiential learning within the firm, while he characterizes imitation as a "learning-by-watching" strategy that involves competitor intelligence, relentless data collection, and importation of new ideas and technologies from external linkages and partners. These studies, however, have not directly touched on the complementarity between imitation and innovation.

More recently, two important lines of research have addressed this topic. In the innovation management literature, the argument is often made that the firms that build on the capability platforms shared by imitation and innovation lead to effective new product development (e.g., Shenkar, 2010; Wu, Zhuo, and Wu, 2017). Shenkar (2010) used the concept of “imovator" to refer to the firms that know "how to develop and leverage the distinct qualities associated with imitation including the ability to conduct broad searches in real-time, work from multiple models, and understand the correspondence between a product and its market" (Shenkar, 2010: 11). The economics literature about competition and innovation, however, provides a different argument. According to the escape competition argument advanced by Aghion et al. (2001), a little imitation is almost always growth-enhancing, and it results in more neck-and-neck competition, which motivates firms to invest in $\mathrm{R} \& \mathrm{D}$ in order to escape rivalry with neck-and-neck rivals. This argument rests on the premise the imitator has lower overall costs and can outbid rivals if combining with innovation.

\section{The Role of Knowledge Search in China's Innovation System}


China's innovation system in the 2000s is characterized by the active roles of governments and public policies featured in three aspects. First, the Chinese government has invested large scale resources in both application-oriented and basic R\&D activities, where state-of-the-art research centers and universities reside ( $\mathrm{Wu}, \mathrm{Zhuo}$, and $\mathrm{Wu}, 2017)$. As a result, universities and public research centres play an important role in generating new knowledge and patents essential for China's national innovative capacity (Hu and Mathews, 2008). Second, the Chinese government's "Go Global" policy encourages high-tech exports that place heavy pressure on Chinese industrial firms to learn to innovation (either by investing more in R\&D or by imitating on even copying readily available technologies created by international counterparts from more developed countries), which helps improve national innovation capacity (Wu, Ma, and Zhuo, 2016). Third, the "Open Door Policy" has attracted trillions of inward foreign direct investments (FDIs) from developed countries that have significantly contributed to the country's ability to produce cuttingedge technologies (Hu and Mathews, 2008; Wu, Ma, and Zhuo, 2016).

Although China innovation system witnesses a surge in patenting activities by Chinese firms and organizations since 2001, not all Chinese firms have been equally benefited. Some Chinese firms are able to search broadly to identify and acquire valuable knowledge and add to their innovative capacity, fostering the development of a strong knowledge base whereas others are not. Some innovation management scholars have analysed factors that inhibit Chinese firms' utilization of imitation and innovation (Bi et al., 2017; Cappelli, Czarnitzki, and Kraft, 2014), among which external knowledge search is a critical boundary factor that affects the joint effect of imitation and innovation on firm performance and growth.

\section{BASIC MODEL}




\section{Supermodularity and Complementarity}

We derive the notion of complementarity from Edgeworth complements. Following the work of Milgrom and Roberts (1990) and Topkis (1978, 1995, 1998), we first build on algebraic lattice theory to show the existence of complementarity. Using algebraic lattice theory, we introduce the basic notations as follows. Let $(Z, \leq)$ denote a lattice, which is a set $Z$ of partial order $\leq$ (for a more mathematical rigorous definition of lattice, see Birkhoff 1967). If $x \in Z$ and $y \in Z$, then the lattice (1) contains the smallest elements, which are larger than both $x$ and $y$, and (2) contains the largest elements, which are smaller than both $x$ and $y$. Let $x=\left(x_{1}, x_{2}, \ldots, x_{n}\right) \in \mathbb{R}^{N}$ and $y=$ $\left(y_{1}, y_{2}, \ldots, y_{n}\right) \in \mathbb{R}^{N}$. Then, $x \leq y$ if $x_{i} \leq y_{i}$ for $i=1, \ldots, n$. In addition, $x$ joins $y$, which we note as $x \wedge y$, which means that the smallest elements are larger than both $x$ and $y$ and where we define the notation as

$$
x \wedge y=\left(\min \left\{x_{1}, y_{1}\right\}, \ldots, \min \left\{x_{n}, y_{n}\right\}\right)
$$

Conversely, $x$ meets $y$, which we note as $x \vee y$ such that that the largest elements are smaller than both $x$ and $y$, where we define the notation as

$$
x \vee y=\left(\max \left\{x_{1}, y_{1}\right\}, \ldots, \max \left\{x_{n}, y_{n}\right\}\right)
$$

A set of choices lying above a set is called a sublattice, a term that Milgrom and Roberts (1995) used to address the type of complementarity. We provide a mathematical definition as follows. Given that $(Z, \leq)$, a sublattice is a subset of $Z$, which is closed under the "meet" and "join" operations. The term $Z$ is a sublattice of $\mathbb{R}^{N}$ if it satisfies $Z \subseteq \mathbb{R}^{N}$, and $x \in Z$ and $y \in Z$ imply that $x \wedge y \in Z$ and $x \vee y \in Z$. Unfortunately, the concept of sublattice is complicated when it is in Euclidian space $\mathbb{R}^{N}$. Therefore, we illustrate its concept in two dimensions. A subset is a sublattice of $\mathbb{R}^{2}$ if and only if the boundary does not consist of a downward-sloping part. Figure 1 illustrates this definition and concept. In the left panel of Figure 1, the subset formed by the four points $(x$, 
$y, x \wedge y$, and $x \vee y)$ is a sublattice of $\mathbb{R}^{2}$. Conversely, in the right panel of Figure 1, the subset formed by the three points $\left(x, y\right.$, and $x \wedge y$ ) is not a sublattice of $\mathbb{R}^{2}$, because the line formed by $y$ and $x$ is downward slopping. The definition of sublattice indicates complementarity because it constrains the choice of $x$ and $y$, which are complementary.

[Insert Figure 1 about here]

As previously discussed, the sublattice characterizes the complementarity as a set. The central concept of the sublattice theory is supermodular, which describes the complementarity of a function. Let $f$ be a real-valued function from $\mathbb{R}^{N}$ to $\mathbb{R}$. If $x \leq y$ implies $f(x) \leq f(y)$, then $f$ is an increasing function. Otherwise, if it implies $(x) \geq f(y)$, then it is a decreasing function. A real-valued function $f$ is supermodular if it satisfies the following condition:

$$
f(x)+f(y) \leq f(x \wedge y)+f(x \vee y) .
$$

Moreover, if $f$ is supermodular, then $-f$ is submodular. We can rearrange Eq. (1) as follows:

$$
\{f(x)-f(x \wedge y)\}+\{f(y)-f(x \wedge y)\} \leq f(x \vee y)-f(x \wedge y) .
$$

The left-hand side indicates the sum of changes of $f$ when its arguments are changing separately. The right-hand side reflects the changes of $f$ when its arguments are changing together. A function is supermodular if its arguments that are changing separately are not larger than its arguments changing together. We can also rearrange Eq. (1) as follows:

$$
f(x \wedge y)-f(y) \geq f(x)-f(x \vee y) .
$$

This equation can provide more intuition on complementarity. For example, if we take $x=$ $\left(x_{a}, x_{b}\right)$ and $y=\left(y_{a}, y_{b}\right)$, with $x_{a} \geq y_{a}$ and $y_{b} \geq y_{a}$, then $x \wedge y=\left(y_{a}, x_{b}\right)$ and $f(x \vee y)=$ $\left(x_{a}, y_{b}\right)$. The inequality of supermodularity implies that

$$
f\left(x_{a}, y_{b}\right)-f\left(x_{a}, x_{b}\right) \geq f\left(y_{a}, y_{b}\right)-f\left(y_{a}, x_{b}\right),
$$


which means that the marginal return of increasing the second argument will increase while the first argument increases from $y_{a}$ to $x_{a}$.

Complementarity does not require $f$ to be differentiable. However, the complementarity is similar to the positive substitution when $f$ are differentiable. For example, suppose that the function $f$ has the Cobb-Douglas functional form $f(x, y)=C x^{\alpha} y^{\beta}$ in which $C, \alpha, \beta>0$. We can then verify that $\frac{\partial^{2} f(x, y)}{\partial x \partial y}=\frac{\partial^{2} f(x, y)}{\partial y \partial x}=C \alpha \beta>0$. More generally, if the real-valued function $f$ is continuous and differentiable, it is complementarity if and only if $\frac{\partial^{2} f(x)}{\partial x_{i} \partial x_{j}} \geq 0$ where $\boldsymbol{x}$ is a vector.

Figure 2 demonstrates that the real-valued function is a supermodular and $x$ and $y$ are complementary as in the Cobb-Douglas case. Figure 2 illustrates a three-dimensional design that plots $z=0.1 x^{2} y^{2.5}$. At a given level of $y$, the function $z$ is always increasing at $x$. At a given level of $y$, the function $z$ is always increasing at $y$. This justifies that the partial derivatives are positive and thus $x$ and $y$ are complementary. To determine how the derivatives relate to sublattice theory, we plot the contour of the function in Figure 3. All the points on the same level curves have the same value of $z$ of the function $f$. The more outside the level curves, the smaller the value of $f$. The four points in this diagram imply that $f(6,4)-f(4,4) \geq f(6,6)-f(4,6)$ because the distance of $f(6,4)$ from $f(4,4)$ is greater than the distance of $f(6,6)$ from $f(4,6)$. This justifies that $x$ and $y$ are complementary, which is in line with sublattice theory.

[Insert Figures $2 \& 3$ about here]

\section{Innovation and Imitation}

Building on the theory of supermodularity and complementarity, we develop a theoretical model to establish a positive substitution relationship between innovation and imitation. Suppose that a 
manufacturing firm is developing a new product and must decide on the strategies for innovation and imitation activities. It is important that we prove it is optimal for the firm to explore the complementarity between innovation and imitation activities when it is deciding on different innovation strategies. Because these two activities may not be measured by continuous variables, we treat them as two choice variables of management strategies.

Following Milgrom and Roberts (1990), we examine the model of strategic choices in the competitive equilibrium analysis that consists of both a supply-side and a demand-side. On the supply side, for simplicity, we assume that the firm is a monopolistic competitor and thus is faced with a downward-sloping demand curve. Because the firm will introduce the innovative product through $R \& D$ activities, we assume that this introduction can be distinguished by two channels: innovation activities and imitation activities. In other words, innovation and imitation are two decision variables of primary concern. We denote the strategies of innovation and imitation as $n$ and $m$, respectively. All other notations appear in the Appendix.

The development of new products involves the average direct cost per product (e.g., the costs of material inputs and labor compensation) denoted by $c$. Innovation and imitation strategies both require R\&D expenditure, though the former requires more expenditure than the latter. We denote this average extra cost as $e(n, m)$, and these costs might include procurement of new devices, extra R\&D personnel, purchasing patents, and so on. We assume that $e(-n,-m)$ is submodular. The function $-e$ is then supermodular. The demand side consists of demand from consumers and capital costs. We assume the capital costs are fixed and denote them as $k$. The demand function is a function of price $(p)$, innovation, and imitation, which we denote as $d=$ $d(p, n, m)$. This is a decreasing function of price because increasing the price of a product will decrease its demand. We offer the following assumption about the property of $d$. 
Assumption: The demand function $d=d(p, n, m)$ is twice continuously differentiable, decreasing in $p$ and supermodular when regarded as a function in $(-p, n, m)$.

A firm's profit equals its operating profit less all the costs, in which profit from sales is $p d(p, n, m)$, and the total cost is $c d(p, n, m)+e+k$. The firm's profit function is given by

$$
\Pi=(p-c) d(p, n, m)-e(n, m)-k,
$$

where $\Pi$ is the firm profit. The profit function can consist of many dimensions of the firm's production strategies. The innovation and imitation strategies can affect customer demand and thus further influence the total sales revenue. However, increasing innovation and imitation strategies increase the cost of R\&D expenditure and capital costs, which in turn reduces the total profit. As the firm is choosing $p$ to maximize profit, we advance the following theorem:

Theorem: $\pi(n, m)=\operatorname{Max}_{p} \Pi(p, n, m)$ is supermodular provided all the variables are nonnegative.

Proof: First, we show that the sum of two supermodular functions is still supermodular, which means that $d(p, n, m)-e(n, m)$ is supermodular. Thus, $\Pi$ is also supermodular. Second, we show that $\pi$ is also supermodular because the maximized $\pi$ over $\Pi$ is also supermodular. For proof, we denote $b \in\{n, m\}$ and $\pi(b)=\operatorname{Max}_{p} \Pi(p, b)$. For all $b$ and $b^{\prime}$, there are $p$ and $p^{\prime}$ with $\pi(b)=\Pi(p, b)$ and $\pi\left(b^{\prime}\right)=\Pi\left(p^{\prime}, b^{\prime}\right)$. Then,

$$
\begin{aligned}
\pi(b)+\pi\left(b^{\prime}\right) & =\Pi(p, b)+\Pi\left(p^{\prime}, b^{\prime}\right) \\
& \leq \Pi\left(\max \left(p, p^{\prime}\right), \max \left(b, b^{\prime}\right)\right)+\Pi\left(\min \left(p, p^{\prime}\right), \min \left(b, b^{\prime}\right)\right) \\
& \leq \pi\left(\max \left(b, b^{\prime}\right)\right)+\pi\left(\min \left(b, b^{\prime}\right)\right),
\end{aligned}
$$

which completes the proof. Then, the theorem implication is that $n$ and $m$ have complementary effects under the supermodular relationship implied by $\pi$. To illustrate this, let the demand 
function be $d=-p+\theta_{1} n+\theta_{2} m$, and the extra cost function be $e=\gamma_{1} n+\gamma_{2} m$. Then, the profit function is

$$
\Pi=(p-c)\left(-p+\theta_{1} n+\theta_{2} m\right)-\left(\gamma_{1} n+\gamma_{2} m\right)-k .
$$

Following Milgrom and Roberts (1990), we write the first-order condition of the profit maximization by choosing the price as the following equation

$$
\frac{\partial \Pi}{\partial p}=\left(-p+\theta_{1} n+\theta_{2} m\right)-(p-c)=0,
$$

which implies that $p^{*}=\left(\theta_{1} n+\theta_{2} m-c\right) / 2$. Then, substituting the optimal $p^{*}$ into the objective function yields

$$
\begin{gathered}
\pi=\left(\frac{\theta_{1} n+\theta_{2} m-2 c}{2}\right)\left(\frac{c+\theta_{1} n+\theta_{2} m}{2}\right)-\left(\gamma_{1} n+\gamma_{2} m\right)-k \\
\frac{\partial^{2} \pi}{\partial n \partial m}=\frac{\theta_{1}^{2} \theta_{2}^{2}\left(\theta_{1} n+\theta_{2} m-2 c\right)\left(c+\theta_{1} n+\theta_{2} m\right)}{4} \geq 0 .
\end{gathered}
$$

Therefore, the partial differentiation is positive, which means that $n$ and $m$ are complements under the profit function.

\section{The General Case}

In our previous discussion, we proved the existence of complementarity between innovation and imitation. It is important to note that in many situations, the continuous variables may not capture the imitation and innovation strategies. As such, we can denote these two activities by 0 and 1 . To apply the complementarity between innovation and imitation, we simplify the imitation and innovation strategies as two dichotomous variables. The theorem indicates that the complementarity relationship is

$$
\pi(1,1)+\pi(0,0) \geq \pi(1,0)+\pi(0,1) .
$$


The theoretical model developed by Athey and Stern (1998) leads to two empirical justifications. First, if $\pi(n, m, X)$ is supermodular in $(n, m, X)$, where $X$ is a set of exogenous variables, the optimal choice under profit maximization is monotone non-decreasing in $X$. In the cross-sectional analysis, $n(X)$ and $M(X)$ will have a positive relationship. In short, the two complementary activities are positively related. However, a positive relationship is not a necessary or sufficient condition for complementarity because estimation bias can lead to a positive relationship when no complementarity exists. Second, if an increase in one of the exogenous variable of $X$ increases only $n$ directly, $m$ will be non-decreasing in that exogenous variable. For example, suppose that increasing sales has a direct positive impact on increasing innovation intensity. Because of the existence of complementarity between innovation and imitation, the imitation intensity will be non-decreasing in sales.

To test the existence of complementarity, we implement two-methods - that is, a direct approach and an indirect approach (Cassiman and Veugelers, 2006). In the direct approach, we test complementarity by regressing the innovation performance on a set of innovation activities (e.g., innovation, imitation). The innovation activities are measured by binary variables for which we established complementarity in Eq. (2). The empirical estimation equation is

$$
\begin{aligned}
\pi^{i}\left(n^{i}, m^{i}, X^{i} ; \theta, \beta\right) & =\left(1-n^{i}\right)\left(1-m^{i}\right) \theta_{00}+n^{i}\left(1-m^{i}\right) \theta_{10}+m^{i}\left(1-n^{i}\right) \theta_{01} \\
& +n^{i} m^{i} \theta_{11}+X^{i} \beta+\varepsilon,
\end{aligned}
$$

where the superscript $i$ stands for the firm (i.e., $n^{i} \in\{0,1\}$ and $m^{i} \in\{0,1\}$ for the $i$ th firm), $X^{i}$ is a set of exogenous control variables, and $\varepsilon$ is the random error. After estimation of the $\theta$ parameters, the test of complementarity is $\theta_{11}-\theta_{10} \geq \theta_{10}-\theta_{00}$. Thus, the direct approach follows the theoretical development of complementarity between innovation and imitation. In the indirect approach, we use external knowledge search as an exogenous variable, and treat it as an exclusion 
restriction. As previously discussed, when complementarity exists, increasing the intensity of external knowledge might increase innovation or imitation without decreasing the other.

The indirect approach is:

$$
\begin{gathered}
n^{i}=z^{i} \gamma_{1}+v_{1}^{i}, \quad n^{i}=1 \text { if } n^{i}>0 \text { and } 0 \text { otherwise; } \\
m^{i}=z^{i} \gamma_{2}+v_{2}^{i}, m^{i}=1 \text { if } m^{i}>0 \text { and } 0 \text { otherwise; } \\
\mathrm{E}\left(v_{1}\right)=\mathrm{E}\left(v_{2}\right)=0 ; \operatorname{Var}\left(v_{1}\right)=\operatorname{Var}\left(v_{2}\right)=1 ; \operatorname{Cov}\left(v_{1}, v_{2}\right)=\rho,
\end{gathered}
$$

where $z$ is the exogenous variable (which in our case is knowledge search). Thus, we run two bivariate probit regressions. If $z$ turns significant in two (innovation and imitation regressions) bivariate probit regressions, the presence of complementarity is justified.

\section{DATA AND METHODS}

\section{Data}

The empirical analyses employed data from an original survey conducted in 2002 by the World Bank in partnership along with China's National Bureau of Statistics (NBS). NBS's administrative authority ensures that it is mandatory for the firms chosen to respond and such responses are mandatory, resulting in a high response rate $(>74 \%)$. The survey covered five manufacturing sectors (electronic equipment, electronic components, consumer products, vehicles and vehicle parts, and apparel and leather goods) and five service sectors (i.e. accounting, advertising and marketing, business logistics, communications, and information technology). ${ }^{1}$ The 1,548 sampled firms were randomly selected from five cities including Shanghai, Chengdu, Tianjin, Guangzhou, and Beijing. Given the research focus of this study on the complementarity effect of imitation and

\footnotetext{
${ }^{1}$ Approximately $66.53 \%$ of the firms in the sample are from the manufacturing sectors, and $33.47 \%$ are from service sectors.
} 
innovation strategy and new product sales, and manufacturing firms tend to report relatively complete information about innovation strategies and R\&D expenditure, we limited our analyses to 1020 manufacturing firms, although our theoretical model could be equally leveraged for service industries. After we deleted missing values, the effective sample consisted of 363 manufacturing firms. We examine firms' innovation strategies in the context of the sales of new products.

\section{Measures}

Accordingly, we distinguish innovation and imitation strategies by how a focal firm develops its new products. An Innovate strategy is implemented when a firm develops new products independently or in cooperation with other firms such as competitors, supplier firms, and client firms. In contrast, an Imitate strategy refers to a firm's imitative actions to other firms (imitatees) particularly those not cooperating with the focal firm's imitative efforts-in developing new products. When the imitatee is not cooperating ${ }^{2}$ with the imitation efforts, a firm can attempt to duplicate a product through three means: (1) by assessing a product already supplied by another firm in the national market and developing its own version, (2) by assessing a product already supplied by another firm in the international market and developing its own version, or (3) hiring key personnel from the imitatee to develop a similar product ${ }^{3}$. For the empirical analysis, we aggregate these mechanisms to arrive at an Imitate strategy that indicates a firm is active on imitation activities whenever it performs at least one of these activities. Innovate and Imitate are nonexclusive. Table 1 reports information on the firms' innovation and imitation activities. About

\footnotetext{
${ }^{2}$ When the imitatee cooperates with the imitator in its imitation effort, the process is considered a technological transfer (Nelson and Winter, 1982).

${ }^{3}$ To address the reviewer's comment with respect to whether hiring key personnel form the imitatee to develop a similar product differs from what is usually understood by imitation, we dropped the item (3) and re-run the analyses. The results dropping the item (3) are consistent with the results keeping it.
} 
three-quarters of sample firms have internal R\&D activities (76\%), and about half cooperate with suppliers, competitors, or client firms to develop new products. More than $40 \%$ of the firms are active in imitative activities. As expected, innovation and imitation are positively correlated $\left(0.18^{*}\right)$. These results are consistent with the complementarity between innovation and imitation activities. The significant and positive correlation between different innovation activities suggests that firms engaging in an innovation strategy simultaneously implement different innovation mechanisms. Similarly, the significant and positive correlation between different imitation activities suggests that firms engaging in an imitation strategy simultaneously implement different imitation mechanisms.

[Insert Table 1 about here]

To test the complementarity, we classify firm strategies into four mutually exclusive categories on the basis of the different combinations of the Innovate and Imitate strategies. Specifically, NoInnovate\&Imitate refers to firms that adopt neither strategy; InnovateOnly refers to firms that adopt only an innovate strategy; ImitateOnly refers to firms that adopt only an imitate strategy; and Innovate\&Imitate refers to firms that adopt both strategies. Table 2 reports the frequency and percentage of firms adopting these exclusive innovation strategies. The first (second) column of Table 2 reports a high number (percentage) of firms that Innovate\&Imitate (177, equivalent to $48.76 \%)$. Only 13 firms (3.58\%) choose ImitateOnly as a strategy, while $141(38.84 \%)$ choose the InnovateOnly strategy. We also find that 32 firms $(8.82 \%)$ are not engaged in either imitation or innovation activities (NoInnovate\&Imitate).

If innovation and imitation are truly complementary, the effect of their complementarity should also appear in the measure of innovation performance. The third column of Table 2 crosstabulates the innovation performance measure - that is, the percentage of sales generated from 
new or substantially improved products introduced in 2000-with different exclusive combinations of the Imitate and Innovate strategies. The results show that NoInnovate\&Imitate and InnovateOnly firms have lower innovation performance than ImitateOnly firms. The most productive innovation strategy is Innovate\&Imitate. Firms that combined both strategies generated $30.28 \%$ of their sales from new or substantially improved products — on average, approximately $14 \%$ higher than firms relying on InnovateOnly strategy. A joint test for equality of means is rejected with a $p$-value of 0.025 , while the test of no complementarity is rejected at the 0.05 significance level.

[Insert Table 2 about here]

\section{Econometrical Analyses}

We developed two methodologies for testing the existence of complementarity; however, we also need to determine the contextual variables that can affect complementarity. We estimate the multinomial logit model as: $\operatorname{Prob}(\mathrm{Y}=j)=\frac{e^{X^{i} \delta^{j}}}{\Sigma_{k} e^{X^{i} \delta^{k}}}$, where $X^{j}$ stands for the vector of characteristics for the $i$ th firm and $j$ stands for a set of strategic choice combinations. In our analysis, the four choices $(k=4)$ are (1) innovation and imitation, (2) innovation but no imitation, (3) imitation but no innovation, and (4) no innovation and no imitation. Compared with the bivariate probit regressions, the multinomial logit model enables us to identify the coefficients of the four strategies differently. One benefit of this model is that it can reveal drivers of exclusive combinations of the four strategies.

In this study, we are particularly interested in the contextual factors that affect the joint effect of imitation and innovation on innovative processes. Although external knowledge search might show the significance in multinomial logit analyses for innovation and imitation results, it 
might not show significance for an imitation-only strategic result. More important, these drivers are indicators of contextual variables, which help us understand how they affect complementarity. To test the moderating effect of external knowledge search, we split the sampled firms into two groups: firms with external search vs. firms without external search and re-ran the analyses for each sub-sample. Moreover, we addressed the potential endogenous issue by following Angrist's (2001) approach and estimated the limited dependent variable with endogenous regressors with the two-step analyses.

\section{EMPIRICAL RESULTS}

\section{The Results of Complementarity of Innovation and Imitation}

In this section, we present the analyses with respect to the effects of different strategies on new product sales. We regress the dependent variable (i.e., \% sales from new products) on four exclusive innovation strategies (Innovate\&Imitate, InnovateOnly, ImitateOnly, and NoInnovate \&Imitate) together with firm characteristics and industry dummies that may affect firm innovation performance. Table 3 presents the definitions of these variables and summary statistics.

[Insert Table 3 about here]

We include several controls that might have an influence on the percentage of sales in the regression analysis. Firms with greater financial performance could have more financial resources devoted to the development of new products, so we include each firm's total sales revenue. Second, to control for the inputs into innovation activities, we include each firm's innovation intensity, which is measured by innovation expenditure divided by total sales revenue. The questionnaire asked for the amount spent on all innovation activities. Third, prior studies have suggested that exporting firms encounter a more competitive environment, which in turn affects their probability 
of adopting an innovation strategy (Cassiman and Veugelers, 2006). We include export intensity, which we calculate by dividing export values by total sales revenue. Fourth, a firm facing intense competition is motivated to improve innovation performance. To control for this effect, we include the number of competitors encountered in a firm's main business line. Moreover, prior studies have suggested that external search affects a firm's innovation performance (e.g., Laursen and Salter, 2006). As such, we include a firm's external search, which we construct as a composite factor consisting of six different search channels (see Table 3). In addition, a firm's R\&D collaboration with other organizations will affect its innovation performance (Ahuja, 2000). Thus, we include a firm's $R \& D$ collaboration, which we measure by aggregating its R\&D collaborations with universities, government research institutions, private research institutions, and private firms. Firm age is another control variable; older firms are likely to have developed competence in innovation, especially in their established business domains (Sorensen and Stuart, 2000). Finally, we include four industry dummy variables using vehicles and vehicle parts as the base group.

We present the results in Table 4. Models 1-4 report the results of ordinary least squares (OLS) regression analyses while Models 5-8 report the results of Tobit regression analyses. The results of the actual test for complementarity (Eq. (1)) are indicated in a separate row at the bottom of Table 4. We first discuss the OLS regression with the Huber-White sandwich estimator (see Models 1-4). Model 1 includes only the four exclusive innovation strategy dummy variables in the regression; Model 2 adds industry dummies; Model 3 adds the variables related to firm-specific characteristics; and Model 4 is the full model, including all the variables.

Consistent with the complementarity hypothesis, the coefficients of Innovate\&Imitate and NoInnovate\&Imitate across Models 1-4 are highly significant and large, while the other coefficients are less significant and lower. The direct test for complementarity $\left(\theta_{11}-\theta_{10}>\theta_{01}-\right.$ 
$\left.\theta_{00}\right)$ is accepted at a 0.01 significance level. The results also show that though they are important characteristic variables, sales, innovation intensity, and export intensity have no significant impact on innovation performance in the regression analyses. The coefficients of industry dummies are not significant.

\section{[Insert Table 4 about here]}

Furthermore, because the dependent variable - the percentage of sales from new products - is left-censored, we also perform the analyses using a Tobit regression. We report the results in Models 5-8. The coefficients of Innovate\&Imitate and NoInnovate\&Imitate are again highly significant and large, reinforcing the large and highly significant impact of Innovate\&Imitate on innovation performance. In contrast, the coefficients of InnovateOnly and ImitateOnly become nonsignificant. The results of the Tobit regression show that the direct test for complementarity $\left(\theta_{11}-\theta_{10}>\theta_{01}-\theta_{00}\right)$ is accepted at a 0.01 significance level, confirming the complementarity between innovation and imitation activities. To be noted, given that the sampled firms include the largest firms, these results hold for the largest firms that usually are close to frontier ${ }^{4}$.

\section{Contextual Variables Affecting Complementarity}

In this section, we examine the probability of adopting different strategies. We search for variables that can explain or affect the joint occurrence of innovation and imitation activities. The innovation literature increasingly emphasizes that knowledge search beyond organizational boundaries is a primary way for firms to quickly develop products (Leiponen and Helfat, 2010; Rosenkopf and Nerkar, 2001). According to the literature we surveyed, a firm's external knowledge search is a

\footnotetext{
${ }^{4}$ The results are available upon request from authors.
} 
common element for innovation and imitation activities (e.g., Chesbrough, 2003, 2011). On the one hand, firms engaged in the innovation process need to obtain expertise that often cannot be generated in-house; thus gaining access to external knowledge and resources is critical for firms to be successful in innovation. On the other hand, firms engaged in the imitation process need to search for products, processes, services, practices, ideas, and models that are worth imitating. We propose that external knowledge search constitutes a firm's absorptive capacity because the ability to exploit valuable knowledge from different external sources depends on its R\&D capabilities. Firms that search broadly may have a greater absorptive capacity that enables them to effectively use different sources of technologies, whereas firms with little external knowledge search may have the lesser absorptive capacity and thus have to search narrowly. Therefore, firms conducting broad external knowledge search are more likely to combine Innovate and Imitate activities because their greater absorptive capacity will increase the marginal returns from Innovate in the presence of Imitate, and vice versa. Following Laursen and Salter (2006), Leiponen and Helfat (2010), and Grimpe and Kaiser (2010), we construct our variable external knowledge search as a composite factor of six different search channels (for the detailed channels, see Table 3). A firm that exploits all six channels of external knowledge search has a value of 6 , while a firm that exploits none of the six external search channels has a 0 value. We use these variables to proxy the firm's scope of external knowledge search.

Next, we include several variables that we expect to affect the adoption of the four exclusive innovation strategies. First, the economics of scale and scope are likely to affect the choice of innovation strategies. Moreover, large firms have more resources and therefore are more likely to devote resources to independent R\&D (Cohen and Levin, 1989; Cohen and Levinthal, 1990; Patel and Pavitt, 1997). We control for a firm's total sales revenue, Sales, in the regression 
models. Second, high innovation expenditure increases the likelihood of engaging in innovation activities, so innovation intensity is another control. Third, the competitiveness of the environment affects a firm's tendency to adopt a specific innovation strategy. For example, a highly competitive environment may drive a firm to adopt an imitation strategy rather than an innovation strategy. We include two variables (competitive intensity and export intensity) to control for a firm's competitiveness in the domestic and international markets separately. The effect of a firm's collaboration with other organizations is not straightforward, as inter-organizational collaboration increases a firm's propensity to engage in innovation activities and also aids the focal firm in imitating its partners' products or technologies. We include a firm's innovative collaboration without predicting a positive or negative effect. Furthermore, we expect older firms to fall into the competence trap, so we control for firm age in the analyses. Finally, we include several industrylevel variables, such as high-tech sectors, and three industry dummy variables.

Table 5 presents the results of the multinomial logit regressions in which we use the four exclusive innovation strategies as the dependent variables. The first column reports the results of the multinomial logit using NoInnovate\&Imitate as the dependent variable, the second column uses InnovateOnly as the dependent variable, the third column uses ImitateOnly as the dependent variable, and the last column uses Innovate\&Imitate as the dependent variable. A firm's external knowledge search has a positive and significant effect on the probability of adopting Innovate\&Imitate strategy. A 10\% increase in external knowledge search increases the likelihood of combining the Innovate and Imitate strategies by $1.5 \%$. In contrast, external knowledge search has a negative and significant effect on the probability of adopting the NoInnovate\&Imitate strategy and the probability of adopting the InnovateOnly strategy. These results confirm the 
importance of external knowledge search for exploiting the joint benefits of innovation and imitation activities.

\section{[Insert Table 5 about here]}

\section{Split Sample Analyses}

Our results from the multinomial logit regression indicate that external knowledge search is an important contextual variable affecting the complementarity between innovation and imitation. This implies that complementarity is relatively more important for firms with a broad scope of external knowledge search than for the rest of the sampled firms. We test this implication by splitting the sample between firms with and without external knowledge search. We report the results in Table 6. The first column reports the results of the sampled firms with external knowledge search, and the second column reports the results of the sampled firms without external knowledge search. Regardless of whether firms conduct external knowledge search, the coefficient of Innovate\&Imitate is positive and significant, and the coefficients of InnovateOnly and ImitateOnly are positive but not significant. However, when we compare the complementarity tests between the two columns, we find that the complementarity between innovation and imitation is stronger for firms with external knowledge search than for firms without external knowledge search.

$$
\text { [Insert Table } 6 \text { about here] }
$$

\section{Addressing Endogenous Concerns}

Potential endogenous issues may arise if a firm's decision to adopt a specific type of innovation strategy in new product development is based on its product innovation performance. To correct 
the potential endogeneity related to the decision to adopt different innovation strategies, we need to identify appropriate instruments for the four innovation strategy decisions (i.e., NoInnovate\&Imitate, InnovateOnly, ImitateOnly, and Innovate\&Imitate). However, appropriate instruments are not easy to find because they must affect the adoption of innovation strategy without affecting innovation performance directly. We follow Angrist's (2001) approach of estimating the limited dependent variable with endogenous regressors to perform a two-step analysis. With the results from the multinomial logit regression analyses (see Table 5), we first construct the predicted values of the four innovation strategy decisions and then use these values as instruments in the innovation performance regression. Table 7 presents the results of the twostep analysis. Model 1 includes the four exclusive innovation strategy dummy variables in the regression, and Model 2 adds firm-specific characteristics. As Table 7 shows, the models are significant. The coefficient of Innovate\&Imitate is highly significant and positive (Model 8.1: $p<$ 0.001; Model 8.2: $p<0.01)$. The direct test for complementarity is also significant $(p<0.05)$. These results provide additional support for the complementarity between innovation and imitation.

[Insert Table 7 about here]

\section{DISCUSSION AND CONCLUSION}

How is imitation tied to innovation? We address this basic question in the context of China's innovation system in the 2000s where Chinese industrial firms simultaneously execute innovation and imitation strategies in their new product developments. We first draw on the lattice theory and supermodularity theory to offer a mathematic illustration of the existence of the complementarity between innovation and imitation strategies. Empirically, we employ original data on Chinese industrial firms' innovation and imitation strategies in the development of new products to provide 
valuable evidence. The results are consistent with the idea that innovation and imitation complement each other in promoting a firm's innovation performance, and external knowledge search strengthens the effect. The findings have important implications for both theory and practice.

First, this research was motivated by an apparent discrepancy between two lines of research in extant researches. Whereas some researchers studying imitators as simple copycats suggest that imitation is a spontaneous and haphazard act impeding innovation, some innovation management researchers have argued that imitation is not contradictory to innovation but rather supportive of it. This discrepancy exists because one line of research treats imitation as a cumber of innovation, and the other line of research considers imitation as part of innovation. Instead, imitation and innovation in this study are interdependent. If either imitation or innovation was considered alone, their joint impact would have not been elucidated. As Levitt (1966: 70) notes, "Hence an affirmative policy of supporting a strategy of imitation in some organized fashion would have the virtue not only of getting necessary imitative activities into motion early, but of communicating to the entire organization that while innovators are valued, so are the creative imitators. It would legitimize systematic imitative thinking as much as the more glamorous innovative thinking." The implication calls into question the two lines of research that have either characterized the two strategies as unrelated to, or as a substitute, for the other. The findings of the imitation-innovation complementarity suggest that imitation is not only an independent strategy, but also is vital to the effectiveness of innovation itself.

Second, the finding in this study of external knowledge search moderating the complementarity effect of innovation and imitation enriches a paucity of literature on the boundary condition of the imitation-innovation link. Although innovation management researchers have argued that imitation and innovation are intertwined, many scholars have remained agnostic with 
respect to external knowledge search that may facilitate or inhibit the interplay of imitation and innovation. Previous studies suggest that broad and deep search has been found to impact innovation performance (Laursen and Salter, 2006; Wu, Lao, Wan, and Li, 2019) and external knowledge search is an important strategic decision (Wu, 2014; Wu and $\mathrm{Wu}, 2014)$. This study draws on these insights to introduce external knowledge search as a boundary condition on the innovation-imitation complementarity relationship. The findings that the imitation- innovation complementarity is context-specific, and external knowledge search is a reinforcement of the innovation-imitation complementarity send a meaningful message to managers on how to effectively utilize the joint benefits of innovation and innovation activities. Excellent innovation depends not only on combining various innovative or imitative strategies, but also on searching, absorbing and using different sources of external knowledge. Effective innovation management thus requires a balanced approach to different innovation strategies along with an open attitude toward different sources of knowledge.

Third, the findings of this study have policy implications. As noted above, the Chinese governments and its public policies shape the national innovation system in the 2000 s. On the one hand, the "Open Door Policy" have attracted trillions of inward foreign direct investments (FDIs) from developed countries. The entries of foreign multinational enterprises have greatly motivated local Chinese firms to imitate and digest foreign counterparts' innovative ideas and technologies and add significant value to their own innovative products ( $\mathrm{Wu}$ and Pangarkar, 2006), but sometimes take a short cut by optimizing knowledge-creation, technologies, and resources for making their products competitive (Bi et al., 2017). Meanwhile, the "Go Global Policy" has encouraged thousands of Chinese firms to embark high-tech exports and motivated them to learn to innovation (either by investing more in $R \& D$ or by imitating on even copying readily available 
technologies created by foreign counterparts), which have significantly contributed to Chinese firms' ability to produce cutting-edge technologies (Hu and Mathews, 2008; Wu, Ma, and Zhuo, 2016). The imitation-innovation complementarity finding provides some evidence for the contention that Chinese latecomers exploit the synergies of imitation and innovation, transforming themselves from imitators to innovators and vibrant competitors in the global market ( $\mathrm{Wu}, \mathrm{Ma}$, and Zhuo, 2016) and, as a result, national innovation system has evolved from a state-sponsored imitation program to the imitation-innovation mixture. The significant moderating effect of external knowledge search complements a small but growing number of studies that have emphasized a balanced approach to external vs. internal knowledge by the Chinese firms (e.g., Wu and $\mathrm{Wu}, 2014$; $\mathrm{Wu}$ et al., 2019), as their rise to be a contender to foreign firms drive the latter to be more innovative in order to maintain their dominant position, which in turn excites many Chinese firms (e.g., Huawei) with the effective imitation-innovation mixture to catch up foreign rivals (Wu and Pangarkar, 2006). As a result, China's innovation system is rising to a global innovation champion.

\section{Implications for Future Research}

The findings of this study provide several directions for further research. First, one important research avenue would be exploring other firm characteristic variables that might affect the complementarity between innovation and imitation. Further work is beneficial in assessing firm effectiveness of strategies in achieving superiority by adopting a complementary approach to imitation and innovation and alternative contextual variable affecting the relationship. Second, while our theoretical model is rigorous and robust, we call for additional empirical work on external knowledge search to create better tools for the four exclusive innovation strategies, to improve the predictive power, and to confirm the robustness of the results. Third, given that a firm 
faces various decision variables, such as shifting markets and technologies, production costs, inventory, and so on, research would benefit from incorporating these variables into the investigation of the dynamic interplay of innovation and imitation. Finally, further exploration of whether the relationship between imitation, innovation, and external knowledge search could be generalized from the manufacturing sector to the service sector would be beneficial. 


\section{REFERENCES}

Aghion, P., Harris, C., Howitt, P. and Vickers, J., 2001. Competition, imitation and growth with step-by-step innovation. The Review of Economic Studies, 68(3), pp.467-492.

Ahuja, G., 2000. Collaboration networks, structural holes, and innovation: A longitudinal study. Administrative Science Quarterly, 45(3), pp.425-455.

Angrist, J.D., 2001. Estimation of limited dependent variable models with dummy endogenous regressors. Journal of Business \& Economic Statistics, 19(1), pp.2-16.

Arora, A. and Gambardella, A., 1990. Complementarity and external linkages: the strategies of the large firms in biotechnology. The Journal of Industrial Economics, pp.361-379.

Athey, S. and Stern, S., 1998. An empirical framework for testing theories about complimentarity in organizational design (No. w6600). National Bureau of Economic Research.

Bi, J., Sarpong, D., Botchie, D., and Rao-Nicholson, R. 2017. From imitation to innovation: The discursive processes of knowledge creation in the Chinese space industry. Technological Forecasting and Social Change, 120, 261-270.

Birkhoff, G., 1967, Lattice Theory, 3rd ed. American Mathematical Soc.

Bolton, M.K., 1993. Imitation versus innovation: Lessons to be learned from the Japanese. Organizational Dynamics, 21(3), pp.30-45.

Cappelli, R., Czarnitzki, D. and Kraft, K., 2014. Sources of spillovers for imitation and innovation. Research Policy, 43(1), pp.115-120.

Cassiman, B. and Veugelers, R., 2006. In search of complementarity in innovation strategy: Internal R\&D and external knowledge acquisition. Management Science, 52(1), pp.68-82.

Chesbrough, H.W., 2003. Open innovation: The new imperative for creating and profiting from technology. Harvard Business Press.

Chesbrough, H., 2011. Open services innovation: Rethinking your business to grow and compete in a new era. John Wiley \& Sons.

Cohen, W.M. and Levin, R.C., 1989. Empirical studies of innovation and market structure. Handbook of Industrial Organization, 2, pp.1059-1107.

Cohen, W.M. and Levinthal, D.A., 1990. Absorptive capacity: A new perspective on learning and innovation. Administrative Science Quarterly, pp.128-152. 
Davidson, C. and Segerstrom, P., 1998. R\&D subsidies and economic growth. The RAND Journal of Economics, pp.548-577.

Ethiraj, S.K., Levinthal, D. and Roy, R.R., 2008. The dual role of modularity: Innovation and imitation. Management Science, 54(5), pp.939-955.

Grimpe, C. and Kaiser, U., 2010. Balancing internal and external knowledge acquisition: the gains and pains from R\&D outsourcing. Journal of Management Studies, 47(8), pp.14831509.

Hu, M. C., and Mathews, J. A. 2008. China's national innovative capacity. Research Policy, 37(9), pp.1465-1479.

Hurley, S. and Chater, N., 2005. Introduction: The importance of imitation. Perspectives on imitation: From Neuroscience to Social Science, pp.1-52.

Iacoboni, M., 2009. Mirroring people: The new science of how we connect with others. Farrar, Straus and Giroux.

Laursen, K. and Salter, A., 2006. Open for innovation: the role of openness in explaining innovation performance among UK manufacturing firms. Strategic Management Journal, 27(2), pp.131-150.

Leiponen, A. and Helfat, C.E., 2010. Innovation objectives, knowledge sources, and the benefits of breadth. Strategic Management Journal, 31(2), pp.224-236.

Lenox, M.J., Rockart, S.F. and Lewin, A.Y., 2006. Interdependency, competition, and the distribution of firm and industry profits. Management Science, 52(5), pp.757-772.

Levitt, T., 1966. Innovative imitation. Harvard Business Review, 44(5), pp.63-70.

Lichtenthaler, U., 2009. Absorptive capacity, environmental turbulence, and the complementarity of organizational learning processes. Academy of Management Journal, 52(4), pp.822-846.

Milgrom, P. and Roberts, J., 1990. The economics of modern manufacturing: Technology, strategy, and organization. The American Economic Review, pp.511-528.

Milgrom, P. and Roberts, J., 1995. Complementarities and fit strategy, structure, and organizational change in manufacturing. Journal of Accounting and Economics, 19(2-3), pp.179-208.

Nelson, R.R., 2009. An evolutionary theory of economic change. Cambridge, MA: Harvard University Press. 
Patel, P. and Pavitt, K., 1997. The technological competencies of the world's largest firms: complex and path-dependent, but not much variety. Research Policy, 26(2), pp.141-156.

Posen, H.E., Lee, J. and Yi, S., 2013. The power of imperfect imitation. Strategic Management Journal, 34(2), pp.149-164.

Rivkin, J.W., 2000. Imitation of complex strategies. Management Science, 46(6), pp.824-844.

Rivkin, J.W., 2001. Reproducing knowledge: Replication without imitation at moderate complexity. Organization Science, 12(3), pp.274-293.

Rosenkopf, L. and Nerkar, A., 2001. Beyond local search: boundary-spanning, exploration, and impact in the optical disk industry. Strategic Management Journal, 22(4), pp.287-306.

Shenkar, O., 2010. Copycats: How smart companies use imitation to gain a strategic edge. Strategic Direction, 26(10), pp.1-16.

Sørensen, J.B. and Stuart, T.E., 2000. Aging, obsolescence, and organizational innovation. Administrative Science Quarterly, 45(1), pp.81-112.

Topkis, D.M., 1978. Minimizing a submodular function on a lattice. Operations Research, 26(2), pp.305-321.

Topkis, D.M., 1995. Comparative statics of the firm. Journal of Economic Theory, 67(2), pp.370-401.

Topkis, D.M., 1998. Supermodularity and complementarity. Princeton university press.

Westney, D.E., 1986. Imitation and innovation (p. 117). Cambridge, MA: Harvard University Press.

Winter, S.G. and Szulanski, G., 2001. Replication as strategy. Organization Science, 12(6), pp.730-743.

Wu, J. 2014. The effect of external knowledge search and CEO tenure on product innovation: Evidence from Chinese firms. Industrial and Corporate Change, 23(1): 65-89.

Wu, J., Harrigan, K.R., Ang, S.H. and Wu, Z., 2019. The impact of imitation strategy and R\&D resources on incremental and radical innovation: evidence from Chinese manufacturing firms. Journal of Technology Transfer, 44(1), pp.210-230.

Wu, J., Lao, K., Wan, F., and Li, JT. 2019. Competing with multinational enterprises' entry: Search strategy, environmental complexity, and survival of local firms. International Business Review, 28(4): 727-738. 
Wu, J., Ma, Z-Z., and Zhuo, S-H. 2016. Enhancing national innovative capacity: The impact of high-tech international trade and inward foreign direct investment. International Business Review, 26(3): 502-514.

Wu, J., and Pangarkar, N. 2006. Rising to the global challenge: Strategies for firms in emerging markets. Long Range Planning, 39(3): 295-313.

$\mathrm{Wu}, \mathrm{J}$. and $\mathrm{Wu}, \mathrm{Z}-\mathrm{F} .2014$. Local and international knowledge search and product innovation: The moderating role of technology boundary spanning. International Business Review, 23(3): $542-551$.

Wu, J., Zhuo, S, and Wu, Z. 2017. National innovation system, social entrepreneurship, and rural economic growth in China. Technological Forecasting and Social Change, 121: 238-250.

Zeng, J., 1995, Innovative vs, Imitative R\&D and Economic Growth. Unpublished Manuscript, University of Western Ontario. 
Table 1. Innovation and Imitation Activities and Correlations

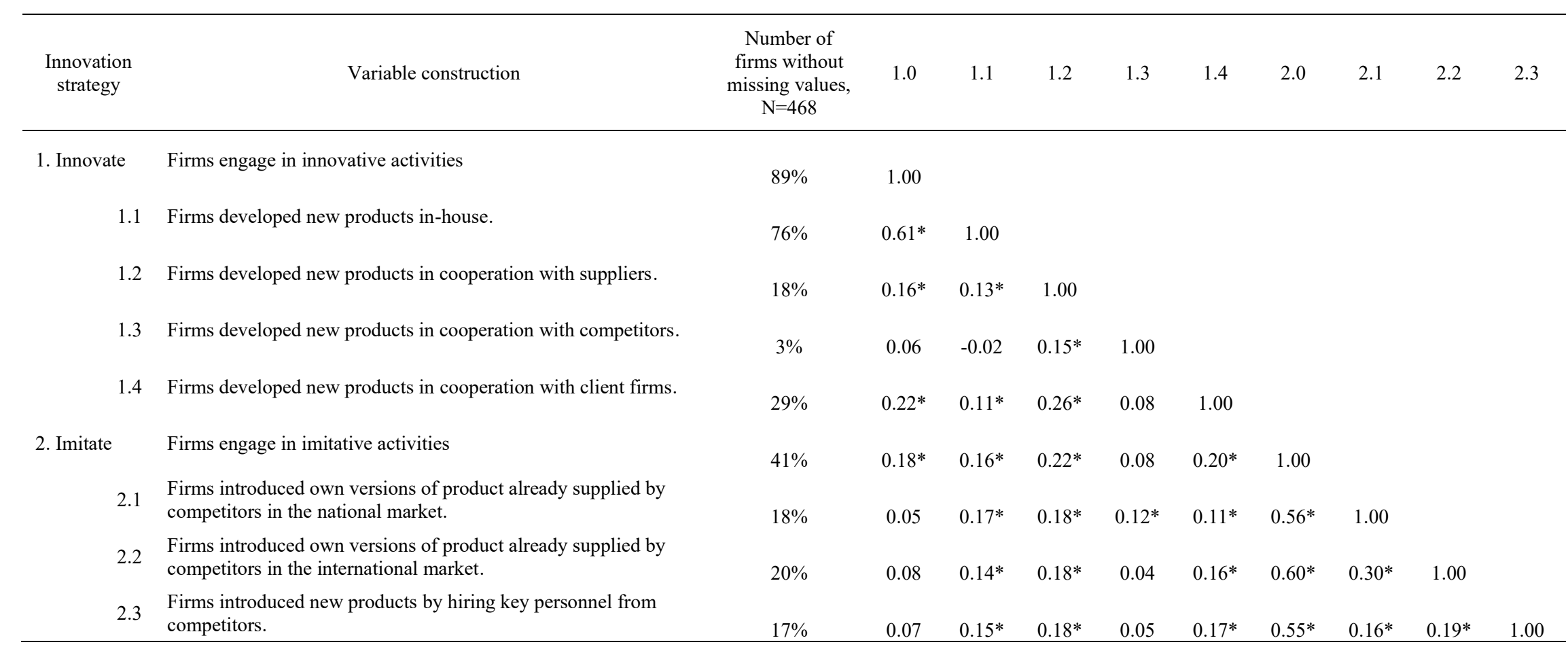


Table 2. Frequency of Innovation and Imitation Strategies

\begin{tabular}{lccc}
\hline \multicolumn{1}{c}{ Innovation strategy and imitation strategy } & Frequency & Percentage & $\begin{array}{c}\text { \% sales from new } \\
\text { products }\end{array}$ \\
\hline NoInnovate\&Imitate & 32 & $8.82 \%$ & $24.09 \%$ \\
InnovateOnly & 141 & $38.84 \%$ & $6.03 \%$ \\
ImitateOnly & 13 & $3.58 \%$ & $24.31 \%$ \\
Innovate\&Imitate & 177 & $48.76 \%$ & $30.28 \%$ \\
Total & 363 & $100 \%$ & $20.10 \%$ \\
& & & $\mathrm{~F}(1,259)=5.02$ \\
Complementarity test & & & $p=0.001$ \\
$\quad$ Innovate\&Imitate - InnovateOnly & & & two-sided \\
\hline
\end{tabular}


Table 3. Variable Definitions, Means, and Standard Deviations

\begin{tabular}{|c|c|c|c|c|c|c|c|}
\hline Variable name & Variable construction & $\begin{array}{c}\text { Sample } \\
\text { mean }\end{array}$ & S.D. & $\begin{array}{c}\text { Mean } \\
\text { Innovation = } 1 \\
(292 \text { firms })\end{array}$ & $\begin{array}{c}\text { S.D. } \\
\text { Innovation }=1\end{array}$ & $\begin{array}{c}\text { Mean } \\
\text { Imitation =1 } \\
\text { (157 firms) }\end{array}$ & $\begin{array}{c}\text { S.D. } \\
\text { Imitation }=1\end{array}$ \\
\hline$\%$ sales from new products & $\begin{array}{l}\text { Percentage of total sales derived from new or } \\
\text { substantially improved products introduced in } 2000\end{array}$ & 27.821 & 24.030 & 27.970 & 24.389 & 14.867 & 13.179 \\
\hline Sales & Total sales revenues in 1999 & 297683 & 1848584 & 313982 & 1967045 & 108789 & 226528 \\
\hline Innovation intensity & Ratio of $R \& D$ expenditures to total sales revenues & 0.077 & 0.562 & 0.085 & 0.598 & 0.095 & 0.801 \\
\hline Export intensity & Ratio of export values to total sales revenues & 0.168 & 0.311 & 0.150 & 0.295 & 0.192 & 0.340 \\
\hline \multirow[t]{7}{*}{ External search } & A composite factor consisting of six items: & & & & & & \\
\hline & $\begin{array}{l}\text { (a) search knowledge from a business or industry } \\
\text { association } \\
\text { (b) search knowledge from attending }\end{array}$ & 0.045 & 0.208 & 0.048 & 0.214 & 0.006 & 0.080 \\
\hline & conferences/seminars & 0.094 & 0.292 & 0.103 & 0.304 & 0.013 & 0.113 \\
\hline & (c) search knowledge from publishing articles & 0.088 & 0.283 & 0.096 & 0.295 & 0.019 & 0.137 \\
\hline & (d) search knowledge from undertaking study tours & 0.369 & 0.483 & 0.418 & 0.494 & 0.185 & 0.389 \\
\hline & $\begin{array}{l}\text { (e) search knowledge from interactions with consultants } \\
\text { (f) search knowledge from universities, research }\end{array}$ & 0.151 & 0.359 & 0.164 & 0.371 & 0.032 & 0.176 \\
\hline & institutes & 0.172 & 0.378 & 0.188 & 0.392 & 0.051 & 0.221 \\
\hline \multirow[t]{5}{*}{ R\&D collaboration } & A composite factor consisting of six items: & & & & & & \\
\hline & $\begin{array}{l}\text { (a) contractual relationship with local university to } \\
\text { perform } R \& D\end{array}$ & 0.245 & 0.431 & 0.264 & 0.441 & 0.127 & 0.334 \\
\hline & $\begin{array}{l}\text { (b) contractual relationship with government research } \\
\text { institution to perform R\&D }\end{array}$ & 0.115 & 0.319 & 0.130 & 0.337 & 0.070 & 0.256 \\
\hline & $\begin{array}{l}\text { (c) contractual relationship with private research } \\
\text { institution to perform } R \& D\end{array}$ & 0.033 & 0.180 & 0.038 & 0.191 & 0.013 & 0.113 \\
\hline & $\begin{array}{l}\text { (d) contractual relationship with private firms to } \\
\text { perform } R \& D\end{array}$ & 0.088 & 0.283 & 0.089 & 0.285 & 0.051 & 0.221 \\
\hline Competitor information & Number of competitors in main business line & 127.737 & 836.298 & 141.593 & 889.455 & 39.764 & 115.367 \\
\hline Employee number & Number of employees & 848.483 & 1715.367 & 842.500 & 1696.933 & 648.522 & 1231.001 \\
\hline Firm age & Number of years since the establishment & 15.042 & 14.584 & 15.682 & 14.921 & 14.484 & 14.808 \\
\hline
\end{tabular}


Table 4. OLS and Tobit Regressions: Dependent Variable \% Sales from New Products

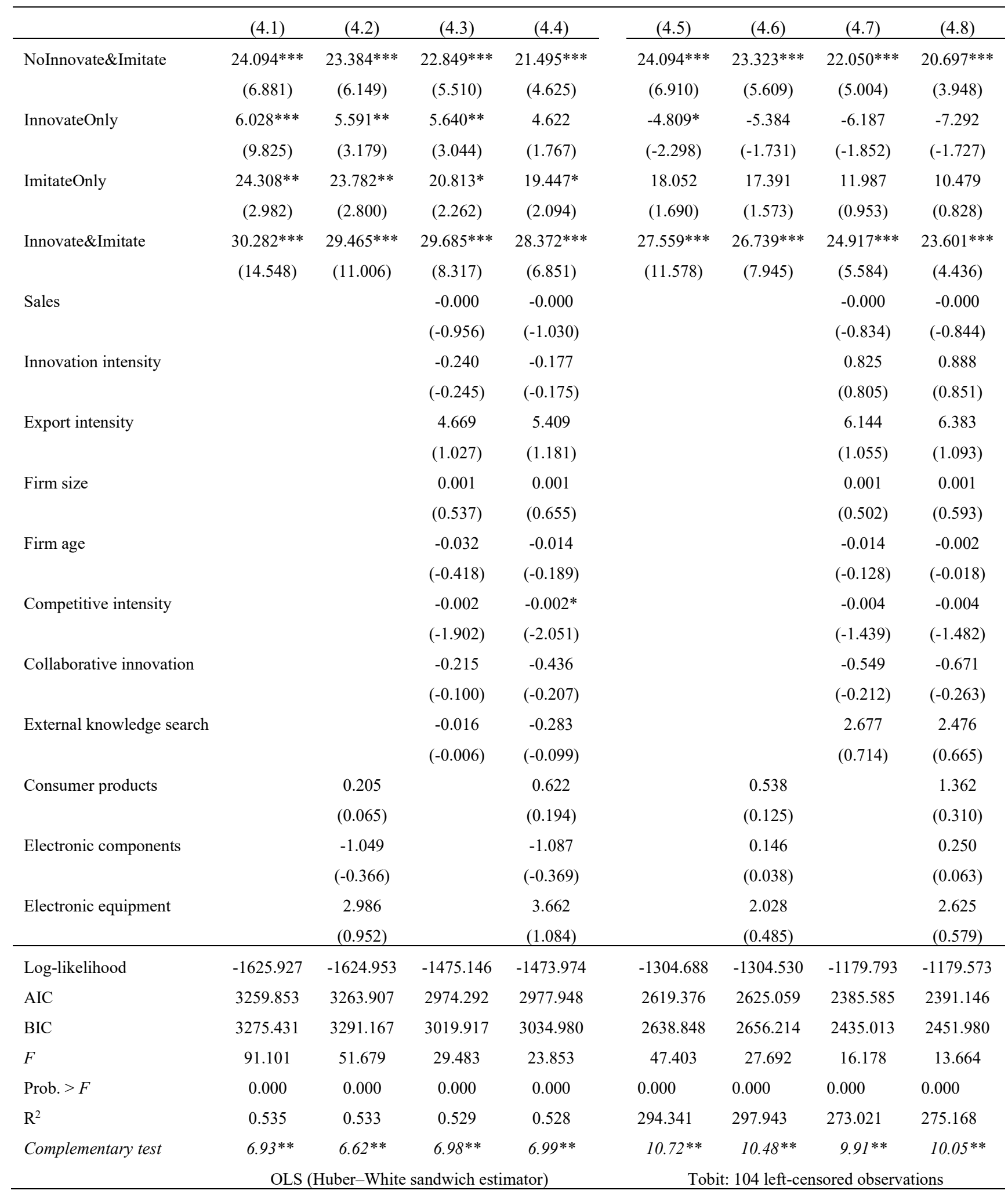

Notes: $\mathrm{N}=363$. Standard errors are in parentheses.

* signifies significance at the $0.05\left({ }^{* *} 0.01 ; * * * 0.001\right)$ level of confidence (two-tailed tests).

The complementarity test: Innovate\&Imitate - InnovateOnly > ImitateOnly - NoInnovate\&Imitate. 
Table 5. Multinomial Logit Using Four Exclusive Innovation Strategies as Dependent Variables: (1) Neither Innovation nor Imitation strategy, (2) Using Innovation Only Strategy, (3) Using Imitation Only Strategy, and (4) Using both Innovation and Imitation strategies,

\begin{tabular}{|c|c|c|c|c|}
\hline & $\begin{array}{c}(5.1) \\
\text { NoInnovate\&Imitate }\end{array}$ & $\begin{array}{c}(5.2) \\
\text { InnovateOnly }\end{array}$ & $\begin{array}{c}(5.3) \\
\text { ImitateOnly }\end{array}$ & $\begin{array}{c}\text { (5.4) } \\
\text { Innovate\&Imitate }\end{array}$ \\
\hline Sales & $\begin{array}{c}0.000^{* *} \\
(3.025)\end{array}$ & $\begin{array}{l}-0.000 \\
(-1.210)\end{array}$ & $\begin{array}{l}-0.000 \\
(-0.760)\end{array}$ & $\begin{array}{l}-0.000 \\
(-0.568)\end{array}$ \\
\hline Innovation intensity & $\begin{array}{l}-5.632 \\
(-1.541)\end{array}$ & $\begin{array}{c}0.210 \\
(1.399)\end{array}$ & $\begin{array}{l}-16.991 \\
(-1.040)\end{array}$ & $\begin{array}{l}-0.125 \\
(-0.871)\end{array}$ \\
\hline Export intensity & $\begin{array}{c}1.000 \\
(1.602)\end{array}$ & $\begin{array}{c}-0.404 \\
(-0.909)\end{array}$ & $\begin{array}{c}-0.475 \\
(-0.566)\end{array}$ & $\begin{array}{c}-0.066 \\
(-0.149)\end{array}$ \\
\hline Firm size & $\begin{array}{c}0.000 \\
(0.070)\end{array}$ & $\begin{array}{l}-0.000 \\
(-1.013)\end{array}$ & $\begin{array}{l}-0.000 \\
(-0.078)\end{array}$ & $\begin{array}{l}0.000 * \\
(2.366)\end{array}$ \\
\hline Firm age & $\begin{array}{c}-0.057 \\
(-1.938)\end{array}$ & $\begin{array}{c}0.001 \\
(0.137)\end{array}$ & $\begin{array}{c}0.009 \\
(0.369)\end{array}$ & $\begin{array}{c}0.004 \\
(0.407)\end{array}$ \\
\hline Competitive intensity & $\begin{array}{l}-0.002 \\
(-0.836)\end{array}$ & $\begin{array}{l}-0.001 \\
(-1.324)\end{array}$ & $\begin{array}{l}-0.005 \\
(-1.103)\end{array}$ & $\begin{array}{c}0.001 \\
(1.730)\end{array}$ \\
\hline Collaborative innovation & $\begin{array}{c}-0.431 \\
(-0.947)\end{array}$ & $\begin{array}{c}-0.273 \\
(-1.206)\end{array}$ & $\begin{array}{c}0.517 \\
(1.380)\end{array}$ & $\begin{array}{c}0.270 \\
(1.323)\end{array}$ \\
\hline External knowledge search & $\begin{array}{r}-3.198^{* *} \\
(-2.762)\end{array}$ & $\begin{array}{c}-1.283 * * * \\
(-4.878)\end{array}$ & $\begin{array}{l}-0.647 \\
(-0.765)\end{array}$ & $\begin{array}{c}1.870^{* * *} \\
(7.216)\end{array}$ \\
\hline Low-tech industry & $\begin{array}{l}-1.435^{*} \\
(-2.414)\end{array}$ & $\begin{array}{l}0.669 * \\
(2.059)\end{array}$ & $\begin{array}{c}-3.850 * * * \\
(-4.806)\end{array}$ & $\begin{array}{c}-1.218^{* * *} \\
(-3.814)\end{array}$ \\
\hline Consumer products & $\begin{array}{c}-0.047 \\
(-0.066)\end{array}$ & $\begin{array}{l}-0.439 \\
(-1.196)\end{array}$ & $\begin{array}{c}1.742 \\
(1.688)\end{array}$ & $\begin{array}{c}0.099 \\
(0.247)\end{array}$ \\
\hline Electronic components & $\begin{array}{l}-1.276 \\
(-1.887)\end{array}$ & $\begin{array}{c}0.571 \\
(1.689)\end{array}$ & $\begin{array}{c}-2.960 * * * \\
(-3.487)\end{array}$ & $\begin{array}{c}-1.253^{* * *} \\
(-3.696)\end{array}$ \\
\hline Electronic equipment & $\begin{array}{c}-0.890 \\
(-1.583)\end{array}$ & $\begin{array}{r}0.246 \\
(0.763) \\
\end{array}$ & $\begin{array}{l}-2.585^{* *} \\
(-2.950) \\
\end{array}$ & $\begin{array}{l}-0.928 * * \\
(-2.979) \\
\end{array}$ \\
\hline Log-likelihood & -72.039 & -193.401 & -42.570 & -188.840 \\
\hline AIC & 168.079 & 410.802 & 109.141 & 401.679 \\
\hline $\mathrm{BIC}$ & 213.704 & 456.427 & 154.766 & 447.305 \\
\hline$\chi^{2}$ & 120.096 & 47.834 & 106.210 & 69.946 \\
\hline Prob. $>\chi^{2}$ & 0.000 & 0.000 & 0.000 & 0.000 \\
\hline
\end{tabular}

Notes: $\mathrm{N}=363$. Standard errors are in parentheses.

$*$ signifies significance at the $0.05(* * 0.01 ; * * * 0.001)$ level of confidence (two-tailed tests) 
Table 6. Subsample Analyses of (1) Firms Conducted External Knowledge Search and

(2) vs. Firms Did not Conduct External Knowledge Search: Dependent Variable \% Sales from New Products

\begin{tabular}{|c|c|c|}
\hline $\begin{array}{l}\text { Dependent Variable: } \\
\% \text { Sales of new } \\
\text { products }\end{array}$ & $\begin{array}{c}(6.1) \\
\text { Firms conducted external knowledge } \\
\text { search }\end{array}$ & $\begin{array}{c}(6.2) \\
\text { Firms did not conduct external knowledge } \\
\text { search }\end{array}$ \\
\hline \multirow[t]{2}{*}{ NoInnovate\&Imitate } & $25.629^{*}$ & $21.549 * * *$ \\
\hline & $(2.311)$ & $(4.465)$ \\
\hline \multirow[t]{2}{*}{ InnovateOnly } & 6.760 & 4.539 \\
\hline & $(1.381)$ & $(1.603)$ \\
\hline \multirow[t]{2}{*}{ ImitateOnly } & 15.524 & 23.057 \\
\hline & $(1.152)$ & (1.934) \\
\hline \multirow[t]{2}{*}{ Innovate\&Imitate } & $28.656^{* * *}$ & $30.189 * * *$ \\
\hline & $(5.135)$ & $(5.638)$ \\
\hline \multirow[t]{2}{*}{ Sales } & -0.000 & 0.000 \\
\hline & $(-1.486)$ & $(0.770)$ \\
\hline \multirow[t]{2}{*}{ Innovation intensity } & $-20.776^{*}$ & 0.905 \\
\hline & $(-2.589)$ & $(0.724)$ \\
\hline \multirow[t]{2}{*}{ Export intensity } & 1.805 & 7.788 \\
\hline & $(0.172)$ & $(1.630)$ \\
\hline \multirow[t]{2}{*}{ Firm size } & 0.002 & -0.000 \\
\hline & (1.199) & $(-0.500)$ \\
\hline \multirow[t]{2}{*}{ Firm age } & -0.097 & 0.048 \\
\hline & $(-0.806)$ & $(0.491)$ \\
\hline \multirow[t]{2}{*}{ Competitive intensity } & -0.002 & $-0.017 * *$ \\
\hline & $(-1.734)$ & $(-2.768)$ \\
\hline \multirow{2}{*}{$\begin{array}{l}\text { Collaborative } \\
\text { innovation }\end{array}$} & 1.676 & -2.976 \\
\hline & $(0.535)$ & $(-1.310)$ \\
\hline \multirow[t]{2}{*}{ Consumer products } & -0.867 & 0.534 \\
\hline & $(-0.168)$ & $(0.122)$ \\
\hline \multirow[t]{2}{*}{$\begin{array}{l}\text { Electronic } \\
\text { components }\end{array}$} & -0.241 & -2.207 \\
\hline & $(-0.048)$ & $(-0.598)$ \\
\hline \multirow[t]{2}{*}{ Electronic equipment } & 3.847 & 3.435 \\
\hline & $(0.723)$ & $(0.782)$ \\
\hline Log-likelihood & -634.006 & -832.996 \\
\hline AIC & 1294.013 & 1693.991 \\
\hline $\mathrm{BIC}$ & 1332.347 & 1739.450 \\
\hline $\mathrm{R}^{2}$ & 0.55 & 0.50 \\
\hline Complementarity test & $4.28 *$ & 3.62 \\
\hline Number of obs. & 141 & 190 \\
\hline
\end{tabular}

Notes: $\mathrm{N}=141$ and 190 for firms with external knowledge search and firms without external knowledge search, separately. Standard errors are in parentheses.

* signifies significance at the $0.05(* * 0.01 ; * * 0.001)$ level of confidence (two-tailed tests).

The complementarity test: Innovate\&Imitate - InnovateOnly > ImitateOnly - NoInnovate\&Imitate. 
Table 7. Two-Step Regression: Dependent Variable \% Sales from New Products

\begin{tabular}{lcc}
\hline & $(8.1)$ & $(8.2)$ \\
\hline NoInnovate\&Imitate & $-24.764^{* * *}$ & -34.615 \\
& $(-3.625)$ & $(-1.745)$ \\
InnovateOnly & -8.103 & -13.056 \\
& $(-0.302)$ & $(-0.402)$ \\
ImitateOnly & -2.480 & -28.032 \\
& $(-0.281)$ & $(-1.189)$ \\
Innovate\&Imitate & $29.882^{* * *}$ & $39.357^{* *}$ \\
& $(9.495)$ & $(2.893)$ \\
Sales & & -0.000 \\
& & $-0.183)$ \\
Innovation intensity & & -0.126 \\
& & $(-0.111)$ \\
Export intensity & & 6.024 \\
Firm size & & $(1.005)$ \\
& & 0.000 \\
Firm age & & $(0.175)$ \\
Competitive intensity & -0.057 \\
Collaborative innovation & & $(-0.644)$ \\
External knowledge search & & $-0.003 *$ \\
Low-tech industry & & $(-1.985)$ \\
$\chi^{2}$ & & -1.065 \\
& & $(-0.433)$ \\
& & -5.845 \\
& & $(-0.729)$ \\
& & -1.147 \\
& & $(-0.482)$ \\
& & 19.91 \\
& & 1693.991 \\
& & $2.42^{*}$ \\
\hline
\end{tabular}

Notes: $\mathrm{N}=190$. Standard errors are in parentheses.

* signifies significance at the $0.05(* * 0.01 ; * * * 0.001)$ level of confidence (two-tailed tests)

The complementarity test: Innovate\&Imitate - InnovateOnly > ImitateOnly - NoInnovate\&Imitate. 
Figure 1. Sublattice and not sublattice.
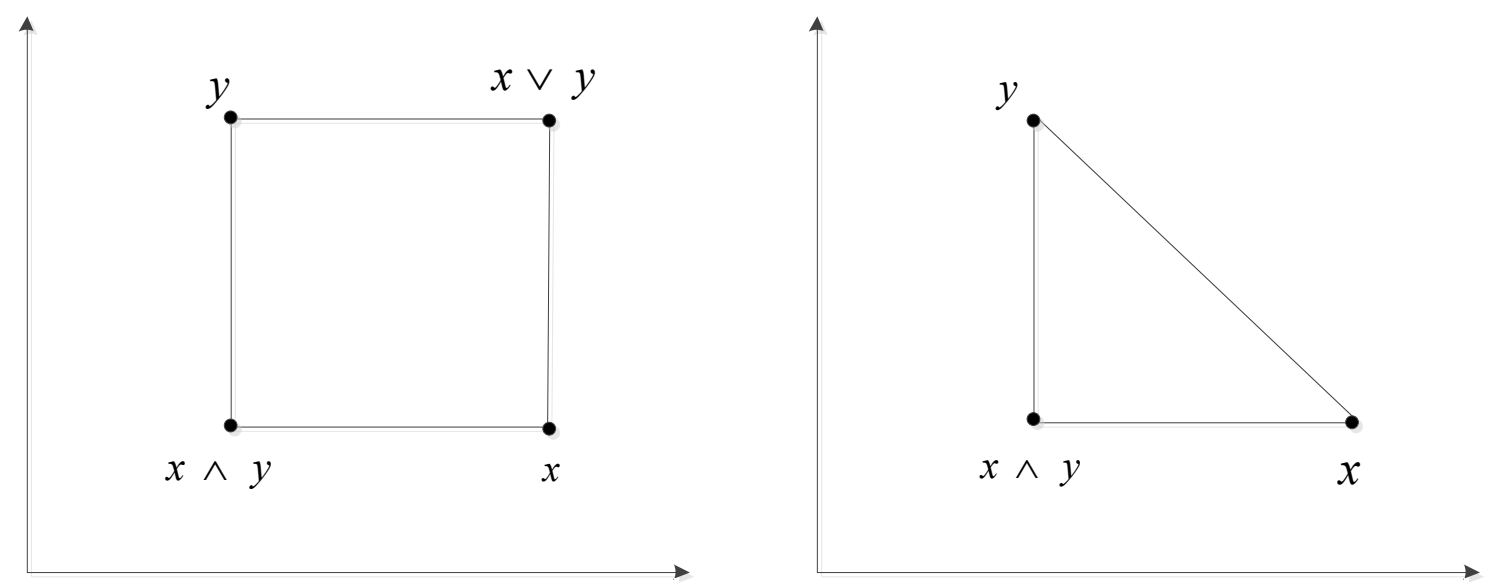
Figure 2. Supermodularity.

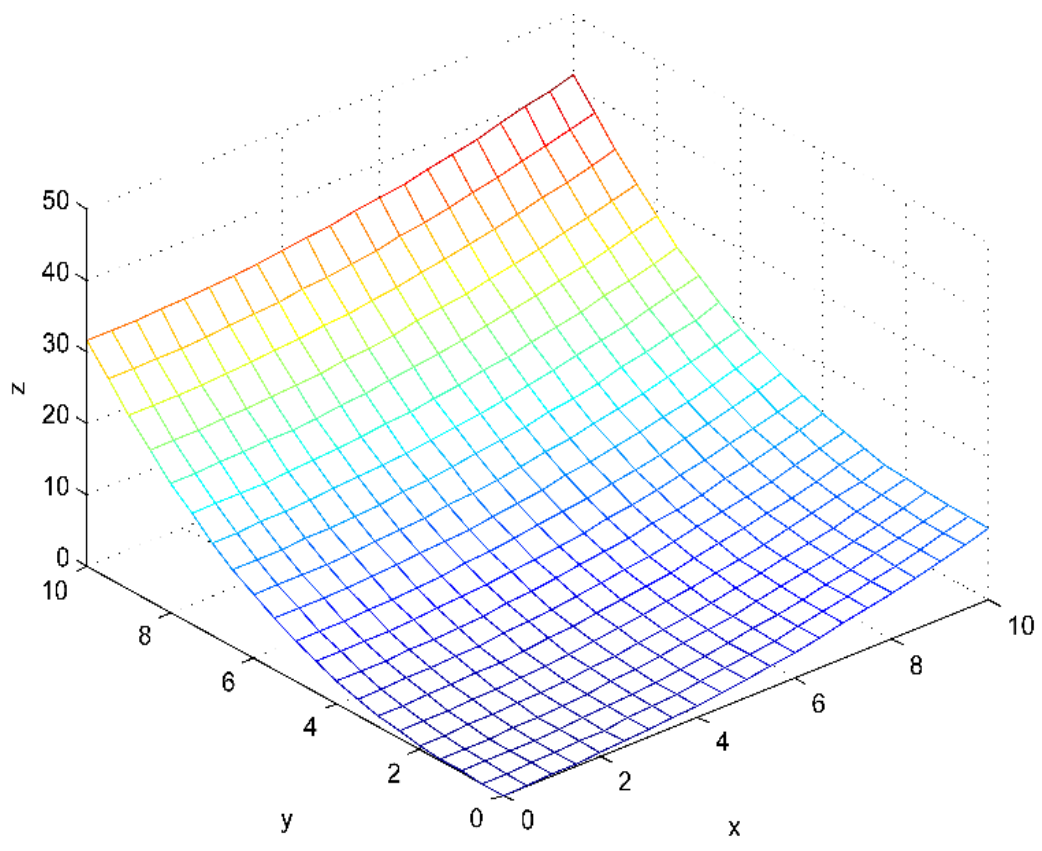


Figure 3. Contour.

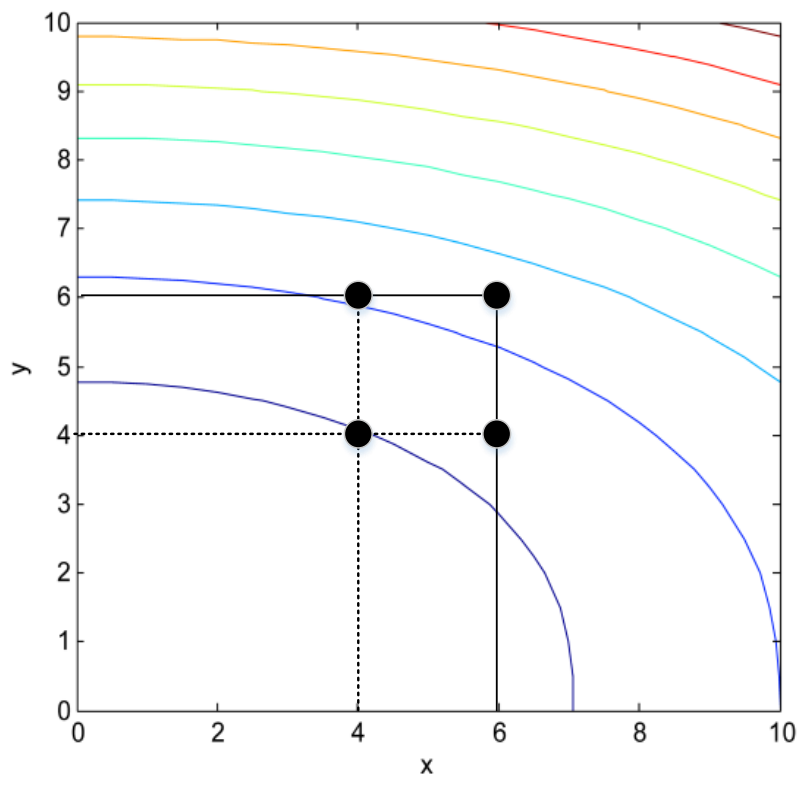


Symbol Interpretation

Decision variables

$p \quad$ Price of average products

$n \quad$ Innovation activities

$m \quad$ Imitation activities

c Average direct cost of production

$e \quad$ Extra average cost of R\&D as $e=e(n, m)$

Parameters

$d \quad$ Demand per product as $d=d(p, n, m)$

$k \quad$ Capital cost as $k$

Others

$\Pi \quad$ Profit of firm

$\pi \quad$ Maximized profit 